(2) Open Access Full Text Article

REVIEW

\title{
Neurogenic overactive bladder in spinal cord injury and multiple sclerosis: role of onabotulinumtoxinA
}

This article was published in the following Dove Press journal:

Degenerative Neurological and Neuromuscular Disease

18 March 2014

Number of times this article has been viewed

KD Ethans ${ }^{1,2}$

AR Casey ${ }^{1,2}$

RJ Bard ${ }^{1,3}$

MP Namaka'

'University of Manitoba, ${ }^{2}$ Section of Physical Medicine and Rehabilitation, Health Sciences Centre, ${ }^{3}$ Section of Urology, Health Sciences Centre,

Winnipeg, Manitoba, Canada
Correspondence: KD Ethans

RRI43A-800 Sherbrook St, Winnipeg.

Manitoba, R3P0CI Canada

$\mathrm{Tel}+$ I 204787 I8I9

Fax + I 204787 |476

Email kethans@hsc.mb.ca
Abstract: People with neurogenic overactive bladder from either multiple sclerosis or spinal cord injury often suffer significant morbidity and decreased quality of life. Here we review the pathophysiology of neurogenic overactive bladder and the impact it can have on people with multiple sclerosis or spinal cord injury. We also address the various traditional treatment options and focus on the use of botulinum toxin A (specifically onabotulinumtoxinA) for this condition.

Keywords: neurogenic detrusor overactivity, overactive bladder, onabotulinumtoxinA, multiple sclerosis, spinal cord injury

\section{Introduction}

Overactive neurogenic bladder is a common problem in people who have multiple sclerosis (MS) and in those with spinal cord injury (SCI). Treatment for neurogenic overactive bladder has improved in recent decades with corresponding reductions in mortality. However, morbidity from neurogenic overactive bladder remains a primary issue for these two patient populations. For example, problems with incontinence may lead to social and vocational isolation, recurrent infections with associated antibiotic resistance, hydronephrosis, renal failure, and other associated issues.

Up to $96 \%$ of individuals with MS report issues with their bladder, ${ }^{1}$ with $41 \%$ reporting significant frequency and 39\% reporting urge incontinence. Urinary problems impact emotional health (31\%), ability to perform household chores $(22 \%)$, and physical recreation (28\%), suggesting substantial disability. Bladder issues also have a significant impact on health in people with SCI. As a result, improving bladder function is a top priority among people living with SCI. ${ }^{2-4}$

In this review, we define neurogenic overactive bladder and discuss the impact this condition has in the MS and SCI populations. We also provide a comprehensive review of the pathophysiology in order to understand the goals of therapy and the treatments available, with a special focus on evidence for the use of onabotulinumtoxinA.

\section{Definitions}

The International Continence Society $(\mathrm{ICS})^{5}$ defines the symptom syndrome of overactive bladder as "symptoms of urgency, with or without urge incontinence, usually with frequency and nocturia". Overactive bladder can be further defined as having neurologic causes or being idiopathic when there is no clear cause. However, the definition given by the ICS is not always applicable to people with SCI or MS, because it implies that 
the person with overactive bladder has sensations of urgency. In reality, many people with these neurologic conditions do not have any sensation in their bladder, of urgency or other. Thus, overactive bladder can be better refined as failure to relax during filling and/or involuntary or reflex contractions of the bladder during filling affecting the deferment of micturition until appropriate. Some refer to the difficulties people have with neurogenic overactive bladder as neurogenic detrusor overactivity; according to the ICS, the term "detrusor overactivity" specifically refers to a urodynamic observation characterized by involuntary detrusor contractions during the filling phase. The ICS further categorizes detrusor overactivity as neurogenic detrusor overactivity (NDO) or idiopathic detrusor overactivity.

\section{Pathophysiology}

Characteristic of central nervous system lesions, the pathological changes associated with SCI and MS typically cause upper motor neuron syndrome. The disruption or lack of descending inhibitory fibers from the brain to the spinal cord leave reflex centers within the spinal cord unchecked, causing spasticity, increased/pathologic reflexes and clonus, as well as weakness. Just as a stretch of a skeletal muscle in the limb of a person with upper motor neuron syndrome may result in an overactive reflex firing without the descending inhibition, stretch of the bladder caused by urinary filling similarly can lead to uninhibited contractions of the detrusor, even at small volumes.

Despite classical teaching that the overactive reflexes in the detrusor are solely due to lack of descending inhibition from the cerebrum and pons, the other contributing factor in people with MS or SCI appears to be the predominance of activity in C-fibers as the primary afferent component of the reflex arc, compared with the usual predominance of A-delta fibers in the non-neurogenic bladder. These C-fibers are relatively "silent" in the non-neurogenic population, and "wake up" or increase in responsiveness after injury to the spinal cord, responding to distension of the bladder with small volumes and causing early stimulation of the reflex arc, which then fires out of control without descending inhibition from the cortex and brainstem. This concept of post-injury shift to a predominance of C-fibers after SCI was first found in spinalized cats, ${ }^{6,7}$ but later confirmed in humans by the observation of significant hyperresponsiveness to intravesical capsaicin (a C-fiber neurotoxin) in people with SCI or MS. ${ }^{8,9}$ Plastic changes with overexpression of other afferent receptors in the suburothelium, such as transient receptor potential cation channel subfamily $\mathrm{V}$ member 1 and $\mathrm{P} 2 \mathrm{X} 3$ purinoreceptor ${ }^{10}$ and neuropeptides such as substance $P$ and calcitonin gene-related peptide after a spinal cord lesion have also been documented. With overexpression of these afferent receptors and increased stimulation of afferents by neuropeptides, the reflex arcs of the bladder are overstimulated and thus have a strong role in the pathophysiology of $\mathrm{NDO}^{11}$ (see Figure 1).

In addition to an overactive detrusor leading to difficulties with storage and incontinence, many people with SCI or MS also have reflex overactive contractions of the external and/or internal sphincter(s), leading to difficulty with complete or total emptying. This is due to a disconnect between the sacral voiding center, spinal sympathetic outflow, and the voiding coordination center in the pons (specifically with suprasacral/infrapontine lesions). This combination of an overactive detrusor causing strong, overactive, and involuntary contractions, in addition to the outlet not relaxing appropriately, is known as detrusor sphincter dyssynergia (DSD). Although some people with MS or SCI have more synergistic overactive voiding and others have an areflexic bladder (eg, those with cauda equina syndrome), DSD is by far the most common presentation of neurogenic bladder in people with MS or SCI. As such, DSD is the primary focus of this paper.

\section{Clinical sequelae of neurogenic overactive bladder with DSD}

Such incoordination of the overactive detrusor and sphincter results in:

- inability to completely empty the bladder when the detrusor does contract because the outlet is also closed, causing urinary stasis and overdistension of the bladder

- high pressures in the bladder due to firing against a closed outlet, resulting in increased ureteric pressures and possibly vesicoureteral reflux, leading to increased risk of hydronephrosis, pyelonephritis, and renal damage

- incontinence, leading to embarrassment, social and vocational isolation, and skin irritation/breakdown

- autonomic dysreflexia (typically for people with SCI lesions at T5 or higher), increased spasticity, and increased neurogenic pain.

\section{Prognosis of kidney function with DSD}

Urodynamic testing can be helpful in both diagnosis and prognosis, thus guiding treatment options. With urodynamic testing, one can measure cystometric capacity (maximum amount of water before leak or other end point such as 


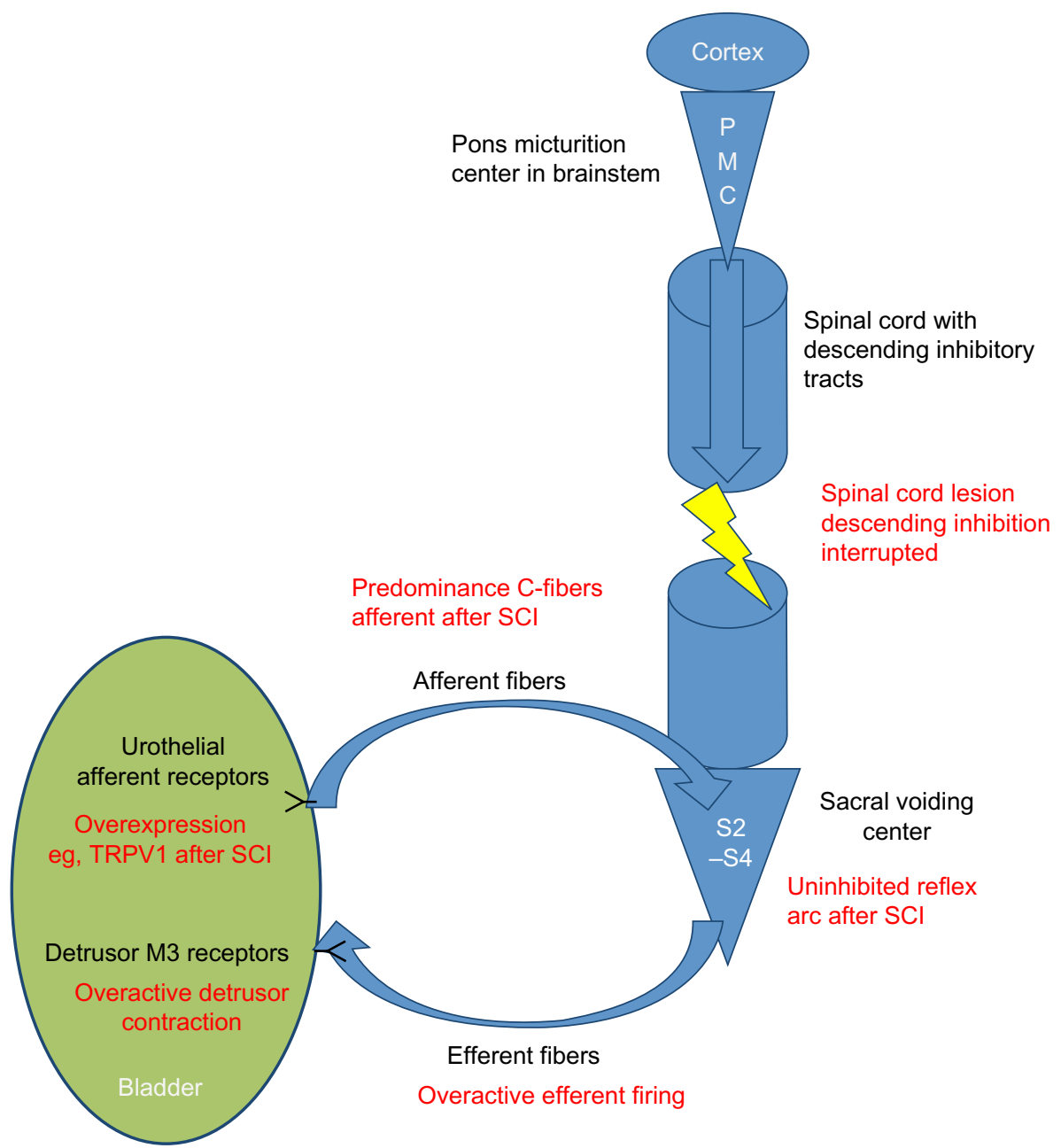

Figure I Mechanism of overactivity of the detrusor in SCI. Black font indicates normal anatomy and red font represents changes after a spinal cord lesion. Abbreviations: M3 receptors, muscarinic subtype 3 acetylcholine receptors; TRPVI, transient receptor potential cation channel subfamily $V$ member I (C-fiber receptor); $\mathrm{SCI}$, spinal cord injury; S2-S4, sacral level 2-4; PMC, pontine micturition center.

patient requests stop of filling), which tends to be small in this population, reflex detrusor volume (when an involuntary contraction first occurs), and maximum detrusor pressure. The detrusor pressure is calculated by subtracting the pressures taken from a catheter in the rectum (abdominal pressure) from the pressures measured from a catheter inside the bladder (intravesical pressure). This subtraction of the abdominal pressure allows for pressures coming from cough and Valsalva maneuvers to be eliminated.

Measuring the detrusor pressure is particularly important, given that the risk of upper tract deterioration increases when the detrusor leak point pressure consistently exceeds $40 \mathrm{~cm} \mathrm{H}_{2} \mathrm{O} .{ }^{12}$ Sustained pressures of $>40 \mathrm{~cm} \mathrm{H}_{2} \mathrm{O}$ can eventually result in decreased transport of urine from the kidney, possible ureteric and renal reflux, and direct transmission of the detrusor pressure to the papillae in the kidney. This can lead to renal damage and failure in these patients, and hence the importance of maintaining lower bladder pressures.

\section{Treatment goals and therapeutic options}

The goals of treatment for neurogenic overactive bladder with DSD are to obtain low-pressure filling, have regular and complete emptying, improve bladder capacity, and avoid incontinence.

Clean intermittent catheterization (CIC) was first described in 1972 as a means of emptying the bladder in those with either upper or lower motor neuron lesions causing bladder dysfunction. ${ }^{13} \mathrm{CIC}$ is now the gold standard for long-term management in people with SCI or MS who cannot otherwise empty the bladder adequately. The goal is for the patient to catheterize every 4-6 hours or frequently enough to keep volumes less than $500 \mathrm{cc}$, and to avoid incontinence 
in between times. If patients are performing CIC but having incontinence in between times, or have evidence of high pressures despite CIC, then medications as described below should be initiated. These medications may also be used in people who still void, but are symptomatic with overactive bladder.

Typical therapy for decreasing detrusor contractions in order to avoid elevated filling pressures is anticholinergic medication. This class of medication primarily targets the muscarinic receptors in the detrusor wall. The most commonly used traditional medication in this class is oxybutynin. However, due to the nonselective nature of blocking muscarinic receptors elsewhere throughout the body, oxybutynin and other traditional anticholinergic medications are associated with many unwanted side effects, including dry mucous membranes, constipation, cognitive dysfunction (due to the ability to cross the blood-brain barrier), worsening of temperature regulation, cardiac arrhythmias, accelerating severity of narrow-angle glaucoma (thus contraindicated in this condition), and others. Given the high incidence of concomitant brain injury in people with traumatic SCI and the high incidence of cognitive impairment in people with MS, the effect of crossing the blood-brain barrier, and thus blocking brain muscarinic receptors, is of particular concern in these two populations. Similarly, people with SCI or MS also typically have a neurogenic bowel, and exacerbation of their symptoms via anticholinergic side effects is often problematic. People with SCI are known to have autonomic dysfunction, making temperature regulation a particular issue that is often exacerbated by medication with anticholinergic properties.

Newer anticholinergic medications are more specific blockers of muscarinic-3 subtype acetylcholine receptors and can help to diminish the numerous side effects of traditional anticholinergics, ${ }^{14}$ such as less drying of the mucous membranes, ${ }^{15}$ and lower the risk of cardiac dysfunction. Furthermore, medications with a larger molecular size are less likely to cross the blood-brain barrier, thereby reducing the risk of cognitive dysfunction. ${ }^{16,17}$ Sustained-release anticholinergic medication options (longacting oral or transdermal patch formulations) can also decrease the side effects typically associated with rapidrelease formulations, because plasma blood levels can be maintained more consistently without the variability found with oral, regularly acting oxybutynin formulations.

A new class of medications, ie, agonists of the $\beta 3$ receptors in the detrusor, are promising for people with MS or SCI. Stimulation of $\beta 3$ receptors enables relaxation of the detrusor during filling, yet appears to cause minimal dryness of the mouth. ${ }^{18}$ Unfortunately, there are no published studies to date of the efficacy of this class of medication in neurogenic overactive bladder.

Despite the advances made in the management of neurogenic bladder care in the last 40 years as described above, many people with MS or SCI have ongoing issues with overactive bladder (incontinence, frequency, urgency, and high detrusor pressures causing reflux, hydronephrosis, and renal failure). Many are intolerant of anticholinergic medications for the reasons discussed above, or continue to have issues of overactive bladder despite high doses of these agents. In the past, the only option was to insert an indwelling catheter, do a sphincterotomy and wear a condom for drainage (in men), or to have bladder augmentation surgery or urinary diversion.

\section{Botulinum toxin A for neurogenic overactive bladder}

The first application of botulinum toxin A for bladder dysfunction was described in the 1980s, with injections of onabotulinumtoxinA into the external urethral sphincter in order to decrease outlet resistance and treat DSD. ${ }^{19}$ This was further explored in a recent meta-analysis of the small number of studies available, totaling 129 subjects, which indicated that this therapy can significantly decrease postvoid residuals at 1 month from $251.8 \mathrm{~mL}$ to $153.0 \mathrm{~mL}$, and decrease detrusor pressures from $88.7 \mathrm{~cm} \mathrm{H}_{2} \mathrm{O}$ to $20.5 \mathrm{~cm}$ $\mathrm{H}_{2} \mathrm{O} \cdot{ }^{20}$ As such, treatment to the detrusor wall itself with onabotulinumtoxinA via cystoscopic needle injections into 20-30 sites throughout the detrusor has emerged as the most useful and efficacious treatment for those intolerant of or not responding to anticholinergic medication.

Intradetrusor onabotulinumtoxinA treatment was first described in an open-label, uncontrolled trial in 2000 by Schurch et al, ${ }^{21}$ with a larger open-label description of 200 patients by Reitz et al in 2004.22 The first multicenter, randomized, placebo-controlled trial of detrusor injections of onabotulinumtoxinA, published by Schurch et al in 2005 , found significant improvements in the onabotulinumtoxinA group, and this effect continued at the study exit of 6 months. ${ }^{23}$ Herschorn et al reported similar efficacy in a placebo-controlled trial, but extended the trial to show an effect lasting for at least 36 weeks from one injection. ${ }^{24}$

Since that time, there have been a number of randomized, placebo-controlled trials confirming the efficacy of onabotulinumtoxinA in the treatment of neurogenic overactive bladder in people with MS or SCI. In particular, 
two large, multicenter, randomized, double-blind, 52-week Phase III studies, ${ }^{25,26}$ performed in people with MS or SCI receiving either $200 \mathrm{U}$ or $300 \mathrm{U}$ of onabotulinumtoxinA, reported dramatic results in both groups when compared with placebo for the primary outcome measure of decreased urinary incontinence at 6 weeks $(P<0.001)$. The combined results also showed a decrease in urinary incontinence episodes by $>20$ per week. ${ }^{27}$ Results for all secondary outcomes were also significant, and included decreased detrusor pressures at first reflex contraction $\left(+1.1 \mathrm{~cm} \mathrm{H}_{2} \mathrm{O}\right.$ in the placebo group, $-32.4 \mathrm{~cm} \mathrm{H}_{2} \mathrm{O}$ in the $200 \mathrm{U}$ group, and $-30.1 \mathrm{~cm} \mathrm{H}_{2} \mathrm{O}$ in the $300 \mathrm{U}$ group) and improved maximum cystometric capacity, ie, improvements of only $11.9 \mathrm{cc}$ in the placebo group, $153.6 \mathrm{cc}$ in the $200 \mathrm{U}$ group $(P<0.01)$, and $163.1 \mathrm{cc}$ in the $300 \mathrm{U}$ group $(P<0.01)$. Scores on the Incontinence Quality of Life (I-QOL) questionnaire ${ }^{28}$ also improved $(P<0.001)$. Duration of effect was based on when subjects asked for retreatment, and was 25.3 weeks in the $200 \mathrm{U}$ group, 24.8 weeks in the $300 \mathrm{U}$ group, and only 13.1 weeks in the placebo group; however, subjects were not allowed to request retreatment before 12 weeks. The most important clinical side effect was the need for de novo catheterization due to new urinary retention and high post-void residuals in the group that could void at baseline (the nonintermittent catheterization group). The need for de novo catheterizations was $7 \%$ in the placebo group, $31 \%$ in the $200 \mathrm{U}$ group, and $44 \%$ in the $300 \mathrm{U}$ group. However, interestingly, the need for de novo catheterizations in these groups did not affect quality of life, ie, these subjects had significant improvement in quality of life scores similar to those who did not have de novo intermittent catheterizations.

Botulinum toxin B (rimabotulinumtoxinB) has also been used for treatment of refractory detrusor overactivity with good efficacy, but seems to have a shorter therapeutic effect than onabotulinumtoxinA, and has been associated with more autonomic side effects. ${ }^{29}$

\section{Mechanism of action}

It is well known that botulinum toxin A works on the efferent peripheral nervous system by blocking release of acetylcholine from presynaptic nerve endings into the neuromuscular junction, leading to a decrease in muscular contraction. However, more recent evidence suggests an additional mechanism in suppressing neurogenic bladder overactivity, with onabotulinumtoxinA targeting the afferent system as well. Apostolidis et al discovered that onabotulinumtoxinA has an inhibitory influence on neurotransmitters and receptors mediating sensory neurotransmission in the bladder wall, specifically the $\mathrm{P} 2 \mathrm{X} 3$ and transient receptor potential cation channel subfamily $\mathrm{V}$ member 1 sensory receptors. ${ }^{30}$ In mouse models, the increased sensitivity of afferent nerves to mechanical stimulation after spinal cord transection was reduced by onabotulinumtoxinA. ${ }^{31}$

\section{Dosing and pattern of injections Dosing}

Doses of onabotulinumtoxinA used in the trials for NDO have varied, usually being $200 \mathrm{U}$ or $300 \mathrm{U}$, with $10 \mathrm{cc}$ dilution per $100 \mathrm{U}$ vial ( $1 \mathrm{cc}$ per $10 \mathrm{U}$ ) and a $1 \mathrm{cc}$ volume injected into 20-30 sites. In the two recent Phase III studies discussed above, ${ }^{25,26}$ there were significant improvements using the $200 \mathrm{U}$ and $300 \mathrm{U}$ doses compared with placebo, but no significant dose-related improvements when comparing the $200 \mathrm{U}$ and $300 \mathrm{U}$ doses. However, the side effects of urinary retention and need for intermittent catheterization de novo among those voiding at baseline were more common in those who received $300 \mathrm{U}(44 \%)$ than in those who received $200 \mathrm{U}(31 \%){ }^{25,26}$ Due to the similarly dramatic efficacy of the $200 \mathrm{U}$ and $300 \mathrm{U}$ doses, but the higher number of adverse events in the $300 \mathrm{U}$ group, regulatory bodies in the USA, Canada, and Europe have approved intradetrusor administration of onabotulinumtoxinA $200 \mathrm{U}$ for treatment of NDO. Some pilot work ${ }^{32}$ investigating the use of a low dose $(100 \mathrm{U})$ of onabotulinumtoxinA in 12 patients with MS and NDO who were still voiding reported that maximum bladder capacity significantly increased, maximum detrusor pressure decreased, and daytime and nighttime frequency, urgency, and pad use significantly decreased. Post-void residual volume increased significantly from an average of $98 \mathrm{cc}$ at baseline to an average of $222 \mathrm{cc}$ at 6 weeks, but decreased to an average of $135 \mathrm{cc}$ by 12 weeks. The average time to reinjection was 8 months. Due to the promising results of this open-label pilot trial, a further, large-scale, randomized, placebo-controlled trial using this dosage is ongoing. ${ }^{33}$

\section{Location of injections}

Several studies of onabotulinumtoxinA have included a protocol of injections that avoid the trigone. The presumed reason for this is to avoid possible vesicoureteric reflux that may be caused by weakening of the trigone musculature. However, more recent descriptions have proposed also injecting the trigone, given the high number of sensory receptors in this area. Abdel-Meguid ${ }^{34}$ objectively evaluated this in a randomized, placebo-controlled study of 36 patients with SCI that compared the effects of $300 \mathrm{U}$ of intradetrusor onabotulinumtoxinA excluding the trigone $(\mathrm{n}=18)$ and 
$200 \mathrm{U}$ to the detrusor as well as $100 \mathrm{U}$ to the trigone $(\mathrm{n}=18)$. The primary outcome measure of incontinence episodes at week 8 decreased by $52.4 \%$ in the non-trigone group versus $80.9 \%$ in the trigone group (number of patients needed to treat 1.91 versus $1.23, P<0.001$ ); complete dryness was achieved in $33.3 \%$ versus $66.7 \%$ of patients (number needed to treat three versus $1.5, P<0.001$ ); and quality of life score was decreased by $46.76 \%$ versus $48.13 \%$ (number needed to treat 2.14 versus 2.08, not significant). Further, there was a significant increase in reflex volumes in the trigone group (60\% in the non-trigone group versus $82.5 \%$ in the trigone group, $P<0.001)$. There was no significant difference with regard to improvement in maximum cystometric capacity (66.2\% versus $68.4 \%$, respectively), or drop in maximal detrusor pressure $(-42.3 \%$ versus $-41.9 \%)$. Importantly, no subjects in this study had worsening or new vesicoureteral reflux, which is the potential concern if not treating the trigone area. Based on the promising results of this small study, ie, an improved effect of onabotulinumtoxinA when the trigone is included, it seems important to further evaluate this concept in larger trials, to ensure that the lack of increased reflux was not a false-negative finding in the trigone-treated group due to small numbers of study participants.

Mascarenhas et $\mathrm{al}^{35}$ reported a prospective study evaluating the effect of intratrigonal injections of onabotulinumtoxinA on the antireflux mechanism and their short-term efficacy. Twenty-one patients with incontinence due to NDO received detrusor injections of onabotulinumtoxinA $300 \mathrm{U}$, including $50 \mathrm{U}$ into the trigone. At baseline, 20 patients had no vesicoureteral reflux and one had grade II unilateral vesicoureteral reflux. Postoperative evaluation revealed no cases of vesicoureteral reflux, and resolution in the one case with this problem at baseline. Hydronephrosis was present in five patients $(23.8 \%)$ before injection but in only one patient (4.8\%) at follow-up evaluation $(P=0.066)$. Therefore, from the few small studies in this area, it seems safe at least to include the trigone in the treatment algorithm.

Another significant area to consider is whether to inject intramuscularly into the detrusor, or whether similar benefits can be achieved by just injecting the suburothelium. Presumably, if some of the major targets for benefit of botulinum toxin A in the bladder lie within the suburothelium (ie, sensory receptors $\mathrm{P} 2 \mathrm{X} 3$ and transient receptor potential cation channel subfamily $\mathrm{V}$ member 1$),{ }^{10,30}$ extensive benefits may be expected from injections in this area. Avoiding the detrusor muscle itself, and thus avoiding weakening it, might be beneficial in people with neurogenic overactive bladder who are still voiding to empty their bladder, so as to avoid retention. A small study of 32 people with SCI and severe neurogenic overactive bladder requiring intermittent catheterization underwent either intradetrusor or subepithelial injections of onabotulinumtoxin $\mathrm{A},{ }^{36}$ and results in the two groups were comparable, with $64.3 \%$ of patients in the intradetrusor group and $88.8 \%$ of those in the suburothelial group being subjectively satisfied with the treatment. Both treatment groups experienced significant improvement with regard to decreasing frequency of catheterization, improved incontinence episodes, increased volumes per catheterization, and cystometric capacity. The only significant difference was that improvement of detrusor compliance was greater in the intradetrusor group. In a study investigating the efficacy and safety of suburothelial injections of different doses of onabotulinumtoxinA for the treatment of detrusor overactivity ( $n=40$ for neurogenic and $n=35$ for idiopathic), doses of $100 \mathrm{U}, 150 \mathrm{U}$, or $200 \mathrm{U}$ were injected at 40 sites. $^{37}$ At 3 months, an "excellent" outcome was obtained in $34.8 \%$, $36 \%$, and $40.7 \%$ of patients treated with $100 \mathrm{U}, 150 \mathrm{U}$, and $200 \mathrm{U}$ of onabotulinumtoxinA, respectively. The duration of therapeutic effect was significantly shorter in the $100 \mathrm{U}$ group than in the $150 \mathrm{U}$ and $200 \mathrm{U}$ groups. Despite the detrusor itself not being injected, there was still a high dose-dependent incidence of new-onset high post-void residual volume $(>150 \mathrm{~mL})$ in all three groups $(30.4 \%$ in the $100 \mathrm{U}$ group, $52 \%$ in the $150 \mathrm{U}$ group, and $72 \%$ in the $200 \mathrm{U}$ group). This study suggests that although suburothelial injections may be helpful by targeting afferent sensory receptors, there is still a relatively high incidence of urinary retention despite not injecting the detrusor muscle.

\section{Long-term efficacy}

In the studies reporting long-term efficacy to date, there seems to be no tachyphylaxis with repeated injections over time, and no loss of duration of effect with subsequent treatments, consistent with other uses of onabotulinumtoxinA.

Persistent effects of repeated injections were found in 17 subjects with $\mathrm{NDO}^{38}$ who had a mean number of 5.4 (range three to nine) injections, for a total of 91 injections. No systemic side effects occurred in this group. The daily number of incontinence episodes decreased from 2.6 at baseline to zero after the first injection, and remained at zero after the last injection. Maximal cystometric capacity and reflex volume increased significantly, and maximal detrusor pressure decreased significantly after the first and last injection when compared with baseline.

A 6-year follow-up study ${ }^{39}$ of 17 people with SCI reported resolution of vesicoureteral reflux in three subjects who had 
this problem at baseline and resolution of the renal pelvis dilatation seen in nine subjects at baseline. There was a decrease in incontinence episodes $(P<0.01)$, an increase in volume at first uninhibited detrusor contraction and in maximum bladder capacity $(P<0.001)$, and a decrease in maximum pressure of uninhibited contractions $(P<0.01)$. Eighty-eight percent of subjects were completely continent, the quality of life index increased significantly, and time between requested injections remained consistent.

Kennelly et al recently reported the results of their interim analysis of an open-label extension of the Phase III clinical trials. In this work, the long-term safety and efficacy of onabotulinumtoxinA was investigated in subjects with NDO, in whom the primary assessment was change from baseline in weekly urinary incontinence episodes at 6 weeks after each treatment. Subjects with MS or SCI underwent treatment with either $200 \mathrm{U}$ or $300 \mathrm{U}$ of onabotulinumtoxinA to the detrusor wall, with treatments repeated for up to five cycles. A total of $387,336,241,113$, and 46 patients received one, two, three, four, and five cycles of onabotulinumtoxinA, respectively, and their weekly number of incontinence episodes decreased markedly at 6 weeks $(-22.7,-23.3,-23.1,-25.3$, and -31.9 for the $200 \mathrm{U}$ onabotulinumtoxinA group in cycles one to five). ${ }^{40}$

\section{Quality of life}

Quality of life is consistently and markedly improved by use of onabotulinumtoxinA for neurogenic overactive bladder, with I-QOL scores being the main measure of quality of life in most studies. Schurch et al reported a study in which quality of life, as measured by I-QOL, was the primary outcome measure and was significantly improved in comparison with placebo for up to 6 months post-injection with doses of either $200 \mathrm{U}$ or $300 \mathrm{U} .^{41}$ Health-related quality of life data have also been reported for the two main trials mentioned above. ${ }^{42,43}$ In these studies, health-related quality of life measures included the total I-QOL score ${ }^{42}$ and three domain scores (avoidance and limiting behavior, psychosocial, and social embarrassment), the modified Overactive Bladder Patient Satisfaction with Treatment Questionnaire (OABPSTQ), and Patient Global Assessment. The primary time point was at post-treatment week 6 . In the study reported by Chancellor et $\mathrm{al},{ }^{43}$ improvements from baseline in I-QOL total score were greater $(P<0.001)$ in both the $200 \mathrm{U}$ and $300 \mathrm{U}$ onabotulinumtoxinA groups versus placebo; also significantly improved in both treatment groups were the OAB-PSTQ $(P<0.001)$ and the Patient Global Assessment $(P \leq 0.001)$. Sussman et $\mathrm{al}^{42}$ looked at the same outcomes in the other Phase III study, and reported that the mean improve- ment in I-QOL total score at weeks 6 and 12 was significantly greater with onabotulinumtoxinA $200 \mathrm{U}$ and $300 \mathrm{U}$ versus placebo ( $\Delta 12.3$ for $200 \mathrm{U}$ and $\Delta 14.9$ for $300 \mathrm{U}$ versus placebo, $P<0.001)$. The OAB-PSTQ results showed improvement in satisfaction in the onabotulinumtoxinA treatment groups $(P<0.001)$, and greater proportions of onabotulinumtoxinAtreated patients reported being somewhat or very satisfied (77.5\% for $200 \mathrm{U}$ and $67.8 \%$ for $300 \mathrm{U}$ versus $39.5 \%$ for placebo), and with significant progress toward or complete achievement of the primary treatment goal (62.9\% for $200 \mathrm{U}$ and $61.6 \%$ for $300 \mathrm{U}$ versus $16.5 \%$ for placebo).

\section{Side effects of intradetrusor onabotulinumtoxin $A$ injections}

The most common adverse event associated with this therapy is urinary tract infection, with an incidence in the large Phase III studies of $36 \%$ in the placebo group, $49 \%$ in the $200 \mathrm{U}$ group, and 53\% in the $300 \mathrm{U}$ group. However, given that all groups had a high incidence of urinary tract infection, this may largely be due to either the disease process or the procedure of detrusor injection itself. The time course of the onset of urinary tract infection is not available, so any conclusions on the cause of this adverse event cannot be made. Increased urinary retention, as defined by post-void residual volume, was $3 \%$ in placebo group, $17 \%$ in the $200 \mathrm{U}$ group, and $21 \%$ in the $300 \mathrm{U}$ group..$^{25,26}$ Dose-dependent increases in urinary retention are seen in other trials as well, as discussed above. Additionally, there was a need to start de novo catheterization in a significant number of subjects who were voiding at baseline, compared with placebo $(44 \%$ of the $300 \mathrm{U}$ dose, $31 \%$ of the $200 \mathrm{U}$ dose group, and $7 \%$ of the placebo group). ${ }^{25,26}$

Of significant concern in these two studies is the increased incidence of muscular weakness, with $1.8 \%$ of the placebo group, $3.8 \%$ of the $200 \mathrm{U}$ group, and $5.5 \%$ of the $300 \mathrm{U}$ group developing increased weakness. It is unknown how many of the subjects suffering from new weakness had MS or SCI, with presumably some of the MS subjects having exacerbations, but regardless, the incidence was higher in the treatment groups. Two of the 28 subjects receiving onabotulinumtoxin $\mathrm{A}$ in the trial reported by Herschorn et $\mathrm{al}^{24}$ also suffered from muscular weakness, both being people with SCI. The seemingly high incidence of new weakness in muscles distant from the injection site warrants further investigation.

\section{Conclusion}

Neurogenic overactive bladder continues to be a source of morbidity and mortality for people with MS and SCI, as well 
as significantly impacting quality of life. However, patients now have access to a treatment that can lead to dramatic improvements in many regards with onabotulinumtoxinA, for up to 9 months or more per treatment. At this point in time, this treatment is second-line to anticholinergic therapy, and will probably remain as such. However, onabotulinumtoxinA, when used in people who have failed or are intolerant of anticholinergic therapy, leads to consistent and dramatic reduction of incontinence, frequency, and damaging high detrusor pressures, as well as significant improvement in bladder volumes and quality of life. Importantly, for these patients with chronic long-term impairment, there is little or no loss of effect over time. As a result of the excellent outcomes of the studies to date, onabotulinumtoxinA into the detrusor is now gold standard therapy for patients with neurogenic overactive bladder who have failed on anticholinergic therapy or are intolerant to it.

\section{Acknowledgment}

The authors acknowledge the Manitoba MS Research Network for its support of this research.

\section{Disclosure}

The authors report no conflicts of interest in this work.

\section{References}

1. Khan F, Pallant JF, Shea TL, Whishaw M. Multiple sclerosis: prevalence and factors impacting bladder and bowel function in an Australian community cohort. Disabil Rehabil. 2009;31:1567-1576.

2. Anderson KD. Targeting recovery: priorities of the spinal cord-injured population. J Neurotrauma. 2004;21:1371-1383.

3. Bloemen-Vrencken JH, Post MW, Hendriks JM, De Reus EC, De Witte LP. Health problems of persons with spinal cord injury living in The Netherlands. Disabil Rehabil. 2005;27:1381-1389.

4. Simpson LA, Eng JJ, Hsieh JT, Wolfe DL. SCIRE Research Team. The health and life priorities of individuals with spinal cord injury: a systematic review. J Neurotrauma. 2012;29:1548-1555.

5. Abrams P, Cardozo L, Fall M, et al. Standardisation Sub-committee of the International Continence Society. The standardisation of terminology of lower urinary tract function: report from the Standardisation Subcommittee of the International Continence Society. Neurourol Urodyn. 2002;21:167-178.

6. Thor K, Kawatani M, de Groat WC. Plasticity in the reflex pathways to the lower urinary tract of the cat during postnatal development and following spinal cord injury. In: Goldberger ME, Gorio A, Murray M, editors. Development and Plasticity of the Mammalian Spinal Cord. Padova, Italy: Liviana Press; 1986.

7. de Groat WC. Central neural control of the lower urinary tract. In: Bock G, Whelan J, editors. Neurobiology of Incontinence. Chichester, UK: John Wiley; 1990.

8. Wiart L, Joseph PA, Petit H, et al. The effects of capsaicin on the neurogenic hyperreflexic detrusor. A double blind placebo controlled study in patients with spinal cord disease. Preliminary results. Spinal Cord. 1998;36:95-99.

9. Fowler CJ, Beck RO, Gerrard S, Betts CD, Fowler CG. Intravesical capsaicin for treatment of detrusor hyperreflexia. J Neurol Neurosurg Psychiatry. 1994;57:169-173.
10. Brady CM, Apostolidis A, Yiangou Y, et al. P2X3-immunoreactive nerve fibres in neurogenic detrusor overactivity and the effect of intravesical resiniferatoxin. Eur Urol. 2004;46:247-253.

11. Smet P, Moore K, Jonavicius J. Distribution and colocalization of calcitonin gene-related peptide, tachykinins and vasoactive intestinal polypeptide in normal and idiopathic unstable human urinary bladder. Lab Invest. 1997;77:37-49.

12. McGuire EJ, Woodside JR, Borden TA, Weiss RM. Prognostic value of urodynamic testing in myelodysplastic patients. J Urol. 2002; 167(2 Pt 2):1049-1053.

13. Lapides J, Diokno AC, Silber SM, Lowe BS. Clean, intermittent self-catheterization in the treatment of urinary tract disease. $J$ Urol. 2002;167:1584-1586.

14. Kessler TM, Bachmann LM, Minder C, et al. Adverse event assessment of antimuscarinics for treating overactive bladder: a network meta-analytic approach. PLoS One. 2011;6:e16718.

15. Herschorn S, Stothers L, Carlson K, et al. Tolerability of $5 \mathrm{mg}$ solifenacin once daily versus $5 \mathrm{mg}$ oxybutynin immediate release 3 times daily: results of the VECTOR trial. J Urol. 2010;183:1892-1898.

16. Pagoria D, O'Connor RC, Guralnick ML. Antimuscarinic drugs: review of the cognitive impact when used to treat overactive bladder in elderly patients. Curr Urol Rep. 2011;12:351-357.

17. Wagg A, Dale M, Tretter R, Stow B, Compion G. Randomised, multicentre, placebo-controlled, double-blind crossover study investigating the effect of solifenacin and oxybutynin in elderly people with mild cognitive impairment: the SENIOR study. Eur Urol. 2013;64: 74-81.

18. Chapple CR, Kaplan SA, Mitcheson D, et al. Randomized double-blind, active-controlled phase 3 study to assess 12-month safety and efficacy of mirabegron, a $\beta(3)$-adrenoceptor agonist, in overactive bladder. Eur Urol. 2013;63:296-305.

19. Dykstra DD, Sidi AA, Scott AB, Pagel JM, Goldish GD. Effects of botulinum A toxin on detrusor-sphincter dyssynergia in spinal cord injury patients. J Urol. 1988;139:919-922.

20. Mehta S, Hill D, Foley N, et al. Meta-analysis of botulinum toxin sphincteric injections in the treatment of incomplete voiding after spinal cord injury. Arch Phys Med Rehabil. 2012;93:597-603.

21. Schurch B, Stohrer M, Kramer G, Schmid DM, Gaul G, Hauri D. Botulinum-A toxin for treating detrusor hyperreflexia in spinal cord injured patients: a new alternative to anticholinergic drugs? Preliminary results. J Urol. 2000;164:692-697.

22. Reitz A, Stöhrer M, Kramer G, et al. European experience of 200 cases treated with botulinum-A toxin injections into the detrusor muscle for urinary incontinence due to neurogenic detrusor overactivity. Eur Urol. 2004;45:510-515.

23. Schurch B, de Sèze M, Denys P, et al. Botulinum toxin type a is a safe and effective treatment for neurogenic urinary incontinence: results of a single treatment, randomized, placebo controlled 6-month study. J Urol. 2005;174:196-200.

24. Herschorn S, Gajewski J, Ethans K, et al. Efficacy of botulinum toxin A injection for neurogenic detrusor overactivity and urinary incontinence: a randomized, double-blind trial. J Urol. 2011;185:2229-2235.

25. Cruz F, Herschorn S, Aliotta P, et al. Efficacy and safety of onabotulinumtoxinA in patients with urinary incontinence due to neurogenic detrusor overactivity: a randomised, double-blind, placebocontrolled trial. Eur Urol. 2011;60:742-750.

26. Ginsberg D, Gousse A, Keppenne V, et al. Phase 3 efficacy and tolerability study of onabotulinumtoxinA for urinary incontinence from neurogenic detrusor overactivity. J Urol. 2012;187:2131-2139.

27. Rovner E, Dmochowski R, Chapple C, Thompson C, Lam W, HaagMolkenteller C. OnabotulinumtoxinA improves urodynamic outcomes in patients with neurogenic detrusor overactivity. Neurourol Urodyn. 2013;32:1109-1115.

28. Wagner TH, Patrick DL, Bavendam TG, Martin ML, Buesching DP. Quality of life of persons with urinary incontinence: development of a new measure. Urology. 1996;47:67-71.

29. Ghei M, Maraj BH, Miller R, et al. Effects of botulinum toxin B on refractory detrusor overactivity: a randomized, double-blind, placebo controlled, crossover trial. J Urol. 2005;174:1873-1877. 
30. Apostolidis A, Popat R, Yiangou Y, et al. Decreased sensory receptors P2X3 and TRPV1 in suburothelial nerve fibres following intradetrusor injections of botulinum toxin for human detrusor overactivity. J Urol. 2005;174:977-982.

31. Ikeda Y, Zabbarova IV, Birder LA, et al. Botulinum neurotoxin serotype A suppresses neurotransmitter release from afferent as well as efferent nerves in the urinary bladder. Eur Urol. 2012;62:1157-1164.

32. Mehnert U, Birzele J, Reuter K, Schurch B. The effect of botulinum toxin type a on overactive bladder symptoms in patients with multiple sclerosis: a pilot study. J Urol. 2010;184:1011-1016.

33. ClinicalTrials.gov. Safety and efficacy study onabotulinumtoxinA for the treatment of urinary incontinence in multiple sclerosis. Identifier NCT01600716. Available from: http://clinicaltrials.gov/show/ NCT01600716. Accessed January 17, 2014.

34. Abdel-Meguid TA. Botulinum toxin-A injections into neurogenic overactive bladder-to include or exclude the trigone? A prospective, randomized, controlled trial. J Urol. 2010;184:2423-2428.

35. Mascarenhas F, Cocuzza M, Gomes CM, Leão N. Trigonal injection of botulinum toxin-A does not cause vesicoureteral reflux in neurogenic patients. Neurourol Urodyn. 2008;27:311-314.

36. Krhut J, Samal V, Nemec D, Zvara P. Intradetrusor versus suburothelial onabotulinumtoxinA injections for neurogenic detrusor overactivity: a pilot study. Spinal Cord. 2012;50:904-907.

37. Kuo HC. Will suburothelial injection of small dose of botulinum A toxin have similar therapeutic effects and less adverse events for refractory detrusor overactivity? Urology. 2006;68:993-997.
38. Karsenty G, Reitz A, Lindemann G, Boy S, Schurch B. Persistence of therapeutic effect after repeated injections of botulinum toxin type A to treat incontinence due to neurogenic detrusor overactivity. Urology. 2006;68:1193-1197.

39. Giannantoni A, Mearini E, Del Zingaro M, Porena M. Six-year follow-up of botulinum toxin A intradetrusorial injections in patients with refractory neurogenic detrusor overactivity: clinical and urodynamic results. Eur Urol. 2009;55:705-711.

40. Kennelly M, Dmochowski R, Ethans K, et al. Long-term efficacy and safety of onabotulinumtoxinA in patients with urinary incontinence due to neurogenic detrusor overactivity: an interim analysis. Urology. 2013;81:491-497.

41. Schurch B, Denys P, Kozma CM, Reese PR, Slaton T, Barron RL. Botulinum toxin A improves the quality of life of patients with neurogenic urinary incontinence. Eur Urol. 2007;52:850-858.

42. Sussman D, Patel V, Del Popolo G, Lam W, Globe D, Pommerville P. Treatment satisfaction and improvement in health-related quality of life with onabotulinumtoxinA in patients with urinary incontinence due to neurogenic detrusor overactivity. Neurourol Urodyn. 2013;32: 242-249.

43. Chancellor MB, Patel V, Leng WW, et al. OnabotulinumtoxinA improves quality of life in patients with neurogenic detrusor overactivity. Neurology. 2013;81:841-848.
Degenerative Neurological and Neuromuscular Disease

\section{Publish your work in this journal}

Degenerative Neurological and Neuromuscular Disease is an international, peer-reviewed, open access journal focusing on research into degenerative neurological and neuromuscular disease, identification of therapeutic targets and the optimal use of preventative and integrated treatment interventions to achieve improved outcomes, enhanced

\section{Dovepress}

survival and quality of life for the patient. The manuscript management system is completely online and includes a very quick and fair peer-review system. Visit http://www.dovepress.com/testimonials.php to read real quotes from published authors. 